\title{
NEM MORTE MATADA, NEM MORTE MORRIDA: CONSIDERAÇÕES SOBRE O CONCEITO DE REGIÃO NA GEOGRAFIA
}

\author{
Bruno Ferreira Soares \\ Universidade Federal de Pernambuco, Recife, PE, Brasil \\ bruno.fsoares@ufpe.br
}

\begin{abstract}
RESUMO
Embora não seja exclusivo da geografia, o conceito de região é um dos elementos-chave desta ciência. Em virtude da polissemia que o envolve e do próprio processo de evolução da ciência geográfica, este conceito está constantemente sendo repensado e redefinido, atravessando momentos em que sua importância é reconhecida em maior ou menor grau, de acordo com a corrente de pensamento geográfico prevalecente. Este artigo propõe-se a refletir em torno do conceito de região a partir da necessidade de tentar responder aos dilemas da complexidade socioespacial contemporânea. Para tanto, utiliza-se como metodologia a revisão literária de diferentes autores dedicados ao tema. Como resultado, destaca-se que o conceito permanece relevante para a ciência geográfica, desde que sejam consideradas as novas formas de articulação regional e os reflexos decorrentes destas.
\end{abstract}

Palavras-chave: Correntes do pensamento geográfico. Regionalização. Articulação regional.

\section{NEITHER SIX, NOR HALF DOZEN: CONSIDERATIONS ON THE CONCEPT OF REGION IN GEOGRAPHY}

\begin{abstract}
Although not unique to geography, the concept of region is one of the key elements of this science. Due to the polysemy that surrounds it and the process of evolution of geographic science itself, this concept is constantly being rethought and redefined, going through moments when its importance is recognized to a greater or lesser degree, according to the prevailing current of geographic thought. This article aims to reflect on the concept of region, from the need to try to respond to the dilemmas of contemporary socio-spatial complexity. To this end, the methodology used was the literary review of different authors dedicated to the theme. As a result, it is highlighted that the concept remains relevant to geographic science, as long as the new forms of regional articulation and the consequences arising from them are considered.
\end{abstract}

Keywords: Currents of geographic thought. Regionalization. Regional articulation.

\section{INTRODUÇÃO}

Refletindo em torno dos conceitos de região e regionalização, dentro de uma perspectiva geográfica contemporânea, Haesbaert (2010) recorre à história do pensamento geográfico para afirmar que a região "morre" e "ressuscita" ao longo das diferentes abordagens assumidas e/ou propostas pelos geógrafos. No capítulo "morte e vida região", embora não mencione no texto, é clara a referência que faz ao poema Morte e Vida Severina, de João Cabral de Melo Neto (2007). O texto, que ora se apresenta, tem como objetivo básico o de também refletir em torno do conceito de região na ciência geográfica, e sua relevância diante do desordenamento socioespacial atual, sem, no entanto, debruçarse sobre recortes espaciais específicos ou oficiais, nem buscar estabelecer conceitos puros ou verdades absolutas. Parte-se do princípio de que "aqueles que aprofundam a questão conceitual e teórica ampliam sua capacidade de investigação e compreensão do mundo, e da geografia em particular" (SUERTEGARAY, 2005, p. 08).

No intuito de alcançar seu objetivo, realizou-se um levantamento bibliográfico em torno das contribuições de diferentes autores, lembrando que, embora seja um dos elementos-chave da geografia, o conceito de região não é exclusivo desta ciência. Assim, o texto foi organizado de forma que, inicialmente, dialogasse sobre como o conceito de região se insere no chamado panorama clássico da geografia. Na sequência, reflete em torno dos momentos em que o conceito "morre" e "ressuscita", dentro das perspectivas geográficas que sucedem-se ao longo do tempo. E, por fim, discute sobre os novos horizontes em torno do conceito de região, apresentando as considerações do autor sobre o tema. Vale ressaltar ainda que, seguindo a relação estabelecida em Haesbaert (2010),

$\begin{array}{llllll}\text { Caminhos de Geografia } & \text { Uberlândia } & \text { v. 22, n. } 84 & \text { dez/2021 } & \text { p. 75-87 } & \text { Página } 75\end{array}$


são adaptados ao texto elementos do poema supramencionado. Adaptação esta que não ocorre apenas como recurso alegórico, mas pelo fato de que, ao narrar o deslocamento de Severino do Sertão para o Litoral Nordestino, o autor aponta para questões socioespaciais, políticas, econômicas, históricas e físicas (naturais/ambientais), além de aspectos urbanos e da relação homem-meio (sociedade-natureza). Questões estas que sempre estiveram presentes nos debates em torno do conceito de região.

Assim, em É A TERRA QUE QUERIAS VER DIVIDIDA, a relação está no desejo do lavrador, que luta pela divisão de terras (reforma agrária) no poema, e as raízes do conceito de região na geografia, que remetem à uma ciência firmada no estudo da diferenciação de áreas. Em ambos os casos (no poema e na ciência geográfica), há relações de poder envolvidas. Em MORTE E VIDA REGIÃO, a referência está no fato de que, assim como no poema, onde a morte, ao mesmo tempo em que encerra a trajetória de uns, é o elemento garantidor da manutenção da vida de outros; a região "morre" e "ressuscita" dentro das próprias correntes que se sucedem ao longo da história do pensamento geográfico. Em MORTE E VIDA BIORREGIÃO, a ideia segue a mesma linha do tópico anterior, ressaltando os momentos em que o conceito de região desfrutou ou não de prestígio na geografia, acrescentando a proposta de adoção da noção de biorregião. Em UMA MORTE MATADA É NECESSÁRIA, a relação está no questionamento de Severino sobre as condições de uma das mortes com que se depara em sua jornada (se de causas naturais ou não), e a necessidade de desconstruir (matar) o conceito de região.

Em ESTÃO CANTANDO EXCELÊNCIAS, a relação apresenta-se na retomada da força do conceito de região e as excelências (incelência ou incelênça ${ }^{1}$ ), cantadas para um defunto no poema. Em SANTOS, a relação está na devoção aos santos presentes em diversas passagens do poema, e as considerações do geógrafo Milton Santos sobre o conceito de região. Em UMA "NOVA" CIGANA, a ideia é ter como pano de fundo as ciganas que fazem uma previsão acerca do futuro de uma criança, para tratar da perspectiva alinhada ao pensamento descolonial, e o conceito de região nesse contexto. Por fim, em A HORA DO JUÍZO, embora tenha em sua essência a ideia de um julgamento, são apresentadas as considerações do autor a partir do diálogo estabelecido no texto, sem, no entanto, buscar estabelecer conceitos puros ou esgotar o debate.

\section{É A TERRA QUE QUERIAS VER DIVIDIDA}

De início, recorre-se ao alerta dado por Gomes (2008), ao afirmar que a ciência não deve atuar como um tribunal, onde, a partir do seu julgamento, vivem e/ou morrem conceitos, sendo salutar o reconhecimento da multiplicidade e da riqueza do conceito de região. No entanto, o auor alerta também que na geografia, o uso dessa noção constitui uma tarefa bem mais complexa, e destaca que uma das alternativas encontradas foi adjetivar a noção de região no intuito de diferenciá-la das demais ciências e do senso comum. Nesse contexto, sob influência da geologia, nasce o conceito de região natural e a ideia de que o meio (natural) exerce um domínio sobre a orientação do desenvolvimento de uma sociedade. Em reposta, surge a noção de região geográfica (região paisagem), questionando a possibilidade de o meio natural explicar as diferenças sociais e a diversidade espacial, e advogando que a região consiste em uma unidade que personifica a ação transformadora do homem sobre um determinado ambiente.

Esse novo modelo se baseava na descrição, com ênfase no trabalho de campo, buscando identificar um produto único e sintético formado pela inter-relação de fatores, uma identidade para região a partir do método regional. Essa proposta ficou conhecida a partir do que se convencionou chamar de "Escola Francesa de Geografia", que teve Paul Vidal de La Blache como um dos principais pilares. Todavia, Gomes (2008) ressalta as contribuições dos alemães Hettner e Dilthey, além de Hartshorne, no intuito de diferenciar o método das ciências humanas (do espírito ou idiográficas), sobretudo da geografia; das ciências físicas e matemáticas (nomotéticas). Corrêa (2000) reforça que, para além da geografia, o termo região também faz parte do linguajar do "homem comum", e alerta que a utilização do termo entre os geógrafos não se faz de forma harmônica, existindo distintas concepções, de acordo com a corrente do pensamento geográfico prevalecente.

No tocante à região, sob uma perspectiva determinista, Corrêa (2000) aponta dois processos fundamentais para a compreensão da história do homem e da própria geografia. O primeiro corresponde à passagem do capitalismo concorrencial para uma fase monopolista e imperialista,

\footnotetext{
1 Acredita-se que a incelência tem o poder de despertar no moribundo o horror do pecado, incitando-o ao arrependimento (RODRIGUES; SILVA, 1981).

$\begin{array}{llllll}\text { Caminhos de Geografia } & \text { Uberlândia - MG } & \text { v. 22, n. } 84 & \text { dez/2021 } & \text { p. 75-87 } & \text { Página } 76\end{array}$
}


enquanto o segundo diz respeito à fragmentação do saber em várias disciplinas. Conforme esse autor, a noção de região natural é fruto direto do determinismo ambiental, que surge no final do século XIX e ganha força nas duas décadas seguintes, quando a ciência geográfica foi impulsionada pela expansão imperialista. Nesse contexto, a região natural passa a ser entendida como uma parte da superfície terrestre dimensionada a partir de escalas territoriais diversas, mas caracterizadas por uma uniformidade, que resultaria da combinação dos elementos da natureza. E que na relação homem/meio (natural), os elementos naturias seriam determinantes, o que justificava importantes facetas do imperialismo.

Como forma de reação, o possibilismo considera a região a partir da evolução das relações entre o homem e a natureza, as quais passam de simples adaptação para uma ação modeladora. Esta, por sua vez, cria paisagens e gêneros de vida próprios e peculiares à cada porção da superfície da Terra. Destarte, a região geográfica, segundo Corrêa (2000), é considerada uma entidade concreta e palpável, oriunda de um processo de evolução, cabendo ao geógrafo o papel de reconhecê-la, descrevê-la e explicá-la, tornando claro seus limites e elementos constituintes. Assim como destacou o momento histórico-político-econômico que caracterizou o surgimento da corrente determinista, e os reflexos para o conceito de região, Corrêa (2000) destaca que a reação francesa ao determinismo ambiental alemão tem como motivação externa a situação de confronto entre os dois países na "corrida colonial".

Para ele, a geografia francesa surge no intuito de cumprir diversos e simultâneos papéis. O primeiro era o de desmascarar o expansionismo germânico (criticando o conceito de espaço vital), sem inviabilizar intelectualmente o colonialismo francês. O segundo buscava abolir qualquer forma de determinação, a partir da ideia de que a ação humana é marcada pela contingência. Enquanto o terceiro enfatizava a fixidez das obras humanas, criadas através de um longo processo de transformação da natureza (CORRÊA, 2000). No contexto possibilista, região e paisagem passam a ser conceitos equivalentes, sendo possível verificar que os elementos humanos passam a ser mais relevantes do que os naturais no processo de geração de regiões geográficas.

Lencioni (1999) destaca que, imbuído do objetivo de construir uma identidade para a geografia e vivendo o momento de unificação de seu país, Ratzel foi fortemente influenciado pela teoria evolucionista. Assim, "acabou construindo uma geografia em que o peso das condições naturais era bastante significativo na organização social dos homens" (p. 83). Todavia, a autora adverte que tal argumentação vai perdendo força ao longo da trajetória do próprio Ratzel, quando passa a reconhecer a importância da história (cultural) na relação homem x meio. Destaca ainda que em aberto confronto com a perspectiva de que as atividades humanas eram determinadas pela natureza, o pensamento possibilista dizia que o meio físico oferecia possibilidades ao homem para o exercício de suas atividades, havendo, assim, escolhas e alternativas diversas nesse processo.

No entanto, Lencioni (1999) afirma que, compartilhando o mesmo tempo histórico, as perspectivas deterministas e possibilistas formaram uma combinação híbrida as quais sustentaram as pretensões expansionistas e dominadoras características da geopolítica desse período. E que, embora sob óticas distintas, a relação homem $x$ meio e o conceito de região como objeto de estudo da ciência geográfica eram elementos comuns à essas duas vertentes.

Sobre as raízes da análise regional e do conceito de região, Haesbaert (2010) afirma que uma das obras pioneiras e mais importantes até hoje é a "Natureza da Geografia", de Richard Hartshorne, publicada em 1939, e considerada por muitos como marco para a construção da geografia moderna. Fortemente inspirado em Hettner (e ambos em Kant), Hartshorne ressalta que a geografia está firmada no estudo da diferenciação das áreas do mundo, uma ciência corológica (Geografia Regional2), com papel fundamentalmente descritivo. Fato que estaria ligado até mesmo aos mais antigos geógrafos como Heródoto e Estrabão. Haesbaert (2010) ressalta ainda que, embora as discussões sobre região na geografia remontem os primórdios da disciplina, seu "período clássico" vai se estabelecer a partir de Humboldt e Ritter, durante a primeira metade do século XIX.

Desse modo, ao longo das primeiras décadas do século XX, período em que a Geografia Regional torna-se quase hegemônica, três geógrafos tiveram grande destaque no debate regional. Mesmo em perspectivas distintas, Paul Vidal de La Blache, Carl Sauer e Richard Hartshorne, enfatizaram o exercício de diferenciação de áreas (regional) como estando no cerne do trabalho do geógrafo. Sobre Paul Vidal de La Blache, Haesbaert (2010) destaca que foi o autor de maior versatilidade conceitual, e,

\footnotetext{
2 Haesbaert (2010) lembra ainda as contribuições de Ptolomeu e Bernard Varenius à essa discussão. $\begin{array}{llllll}\text { Caminhos de Geografia } & \text { Uberlândia - MG } & \text { v. 22, n. } 84 & \text { dez/2021 } & \text { p. 75-87 } & \text { Página } 77\end{array}$
} 
a partir das leituras em que o conceito de região esteve no centro de sua obra, propõe uma divisão em três fases, onde este conceito foi percebida sob óticas distintas (Quadro 1).

\begin{tabular}{|c|c|c|}
\hline Fase & Concepção de Região & $\begin{array}{l}\text { Obra característica dessa } \\
\text { fase }\end{array}$ \\
\hline $1^{\mathrm{a}}$ & $\begin{array}{l}\text { Pautada em um determinismo físico-natural, rejeita as } \\
\text { divisões político-administrativas como base à } \\
\text { regionalização e propõe a valorização das unidades } \\
\text { fisiográficas. }\end{array}$ & $\begin{array}{l}\text { As divisões fundamentais do } \\
\text { território francês (1888). }\end{array}$ \\
\hline $2^{\mathrm{a}}$ & $\begin{array}{l}\text { Há uma espécie de transição da região de bases naturais } \\
\text { para uma região definida a partir da ação humana, ou } \\
\text { resultante da relação homem-meio. }\end{array}$ & $\begin{array}{l}\text { Tableau de la Géographie de } \\
\text { la France (1903) e na } \\
\text { conferência "Os pays da } \\
\text { França" (1904) }\end{array}$ \\
\hline $3^{\mathbf{a}}$ & $\begin{array}{l}\text { Ocorre a introdução da concepção de região econômica e } \\
\text { de região funcional, através da concepção de "nodalidade". }\end{array}$ & Régions Françaises (1917) \\
\hline
\end{tabular}

Fonte: Adaptado pelo autor a partir de Haesbaert (2010).

Diante dessas fases, Haesbaert (2010) entende que, assim como um legado rico e múltiplo de Vidal de La Blache, é possível evidenciar também que, ao longo da história do pensamento geográfico, a região "morre" e "ressuscita" por meio de distintas abordagens assumidas e/ou propostas pelos geógrafos.

\section{MORTE E VIDA REGIÃO}

Conforme Haesbaert (2010), é razoável delimitar três grandes momentos em que foi decretada a "morte" da região na ciência geográfica, sendo necessário compreendê-los para, em seguida, vislumbrar os caminhos percorridos para a sua "ressurreição". Os primeiros a decretarem a "morte" da região foram os geógrafos quantitativistas ou neopositivistas, onde a noção de região passa a ser reduzida a um instrumental metodológico, baseado em uma operação de "regionalização" em um sentido amplo e abstrato. Nas palavras de Gomes (2011, p. 254), "a visão sistêmica, a utilização de modelos e a submissão à lógica matemática penetram fortemente nas ciências naturais e sociais a partir dos anos cinquenta. É neste contexto que se faz a passagem de uma geografia clássica para uma geografia dita moderna".

Essa perspectiva parte do pressuposto de que a classificação consiste em um agrupamento de objetos (municípios, por exemplo), de acordo com suas semelhanças ou relações. Assim, "seleciona-se uma "característica diferenciadora", comum a todos os objetos, a fim de agrupá-los em classes que, por sua vez, podem ser hierarquizados em diversas "ordens", cada uma com um número "x" de "tipos" ou "regiões"' (HAESBAERT, 2010, p. 45). Todavia, esta visão que associa à região um recorte espacial, produzido a partir de uma regionalização (como método e instrumento analítico), não ficou restrita ao enfoque neopositivista. Reverberando também no que, para Haesbaert (2010), representou a ressureição da região dentro dessa própria corrente, a partir da ideia de funcionalismo. "Aparecem, assim, as "regiões funcionais", [...] segundo a qual um centro polarizador urbano estende seu raio de influência sobre um espaço "regional", admitindo zonas de sobreposição a outras regiões funcionais" (p. 47). Nessa abordagem, sob a ótica da análise regional, o papel que a cidade exerce na organização do espaço ao seu redor, de sua área de influência, torna-se o elemento central do que se convencionou chamar de estudo das regiões polarizadas (funcionais).

Sobre esse período, Corrêa (2000) novamente destaca o momento histórico-político-econômico-social. Segundo ele, após a Segunda Guerra Mundial, "verifica-se uma nova fase de expansão capitalista. Ela se dá no contexto de recuperação econômica da Europa e da "guerra fria", envolvendo maior concentração de capital e progresso técnico, resultando na ampliação das grandes corporações já existentes" (p. 06). O autor destaca que essa expansão difere da acorrida no século anterior por não estar mais atrelada à conquista territorial, o que provoca um desmantelamento dos impérios coloniais, e o estabelecimento de uma nova divisão social e territorial do trabalho, envolvendo introdução e difusão de novas culturas, industrialização, urbanização e outras relações espaciais. Para Corrêa (2000), a geografia a partir da década de 1950 ascende com um papel ideológico a ser cumprido, o de justificar a expansão capitalista e dar esperança aos "deserdados da terra", onde o subdesenvolvimento era visto como um estágio necessário para o país alcançar, em pouco tempo, o patamar de desenvolvido.

$\begin{array}{llllll}\text { Caminhos de Geografia } & \text { Uberlândia - MG } & \text { v. 22, n. } 84 & \text { dez/2021 } & \text { p. 75-87 } & \text { Página } 78\end{array}$


Com fortes críticas ao paradigma possibilista e ao trabalho de Hartshorne, a nova geografia busca leis ou regularidades por meio do emprego de técnicas estatísticas e modelos normativos (GOMES, 2011). E nesse sentido, as regiões passam a ser definidas pela aplicação de técnicas estatísticas, nas quais o propósito de cada pesquisador nortearia os critérios a serem selecionados para dividir a região. Portanto, "ao contrário da região vidaliana, a da nova geografia não é considerada uma entidade concreta, e sim uma criação intelectual balizada por propósitos especificados" (CORRÊA, 2000, p. 07).

Durante os anos setenta do século XX, esta percepção é alvo de severas críticas, sobretudo por criar regionalizações amparadas em modelos econômicos nos quais a dinâmica de mercado seria o pressuposto da organização espacial. E assim como a geografia quantitativa, a geografia crítica de perspectiva marxista surge e também traz consigo o movimento de "morte" e "ressurreição" da região. A crítica que a corrente anterior destinava à região na perspectiva da Geografia Regional Clássica é mantida, sobretudo nos trabalhos de Yves Lacoste e a ideia de região como um conceito obstáculo. Todavia, a "morte" da região pela perspectiva marxista é decretada também por meio de uma base mais concreta, a partir da difusão das relações econômicas capitalistas homogeneizadoras, tendo como referência, via de regra, os Estados Unidos da América (HAESBAERT, 2010).

A esse respeito, Corrêa (2000) lembra que as origens da geografia crítica se situam no final do século $\mathrm{XIX}$, com os anarquistas Élisée Reclus e Piotr Kropotkin. E que embora tenha sido "submergida" pela geografia oficial, segundo ele "vinculada aos interesses dominantes" (p. 17), a geografia crítica não só contestava o pensamento dominante, mas estava comprometida com um processo de transformação social. Sobretudo em virtude das tensões sociais que se agravavam a partir da segunda metade da década de 60. De acordo com o autor, era necessário a geografia se reinventar, sob o risco de não dar conta da realidade. Assim, uma geografia crítica começa a se esboçar, "congregando geógrafos de mentes abertas, que tinham se dedicado a nova geografia, como Willian Bunge e David Harvey, ou que tinham uma posição política de esquerda na geografia herdeira das tradições vidalianas, a exemplo de Yves Lacoste" (CORREAA, 2000, p. 18).

A reinterpretação de aspectos abordados nas correntes anteriores, com base na teoria marxista, está entre as principais contribuições da geografia crítica. Em relação ao conceito de região, Corrêa (2000) adverte para a necessidade de inserí-lo em um quadro teórico amplo, que possa dar conta da diversidade da superfície da Terra sob a ação do homem ao longo do tempo. Assim, aponta para a lei do desenvolvimento desigual e combinado, em que a região se caracteriza em virtude da sua inserção na divisão nacional e internacional do trabalho, além de distintas relações de produção. Nesse sentido, os dois aspectos citados traduzir-se-ão tanto em uma paisagem como em um problema específicos de cada região. Tal problemática teria como pano de fundo as especificidades dos embates estabelecidos entre elites regionais e o capital externo à região, além dos conflitos entre as distintas classes que a compõem.

Lencioni (1999), destaca que em meio a um turbilhão de críticas em relação ao progresso técnico e a riqueza da sociedade, em contraste com a pobreza das massas populares, sobretudo no chamado "terceiro mundo", o pensamento marxista passa a fazer parte da discussão dos centros intelectuais. E que embora a região não constitua uma categoria de análise marxista, a perspectiva geográfica influenciada pelo marxismo concebeu a região como parte de uma totalidade. Todavia, diferente das correntes anteriores, não como uma totalidade harmônica e sim uma totalidade histórica, sepultando a ideia de neutralidade da ciência e introduzindo novas categorias de análise ao estudo regional.

Para Gomes (2008, p. 66), a geografia crítica (ou radical) advoga que a regionalização deve ter por base aquilo que é essencial no processo de produção do espaço, a divisão socioespacial do trabalho. "Qualquer outro tipo de regionalização que não leve em conta este aspecto fundamental passou a ser vista, sob este novo ângulo crítico, como um produto ideológico que visa esconder as verdadeiras contradições das classes sociais em sua luta pelo espaço". Para Haesbaert (2010), a partir de trabalhos dos autores que denomina "marxistas inovadores", sobretudo de Gramsci e a "questão meridional", o conceito de região é retomado a partir de duas vertentes. A primeira, onde a região é vista como produto da divisão territorial do trabalho; e a segunda, que enfatiza os movimentos sociais, sobretudo os regionalismos. Entretanto, "poucos foram aqueles que trabalharam numa perspectiva explicitamente gramsciana" (HAESBAERT, 2010, p.57). A relevância da geografia crítica no debate sobre o caráter ideológico dos modelos que naturalizam o capitalismo como única forma de desenvolvimento é inegável. Contudo, para Gomes (2008), do ponto de vista metodológico, o que diferencia a geografia crítica da sua antecessora são os critérios estabelecidos, a escolha do conteúdo a ser regionalizado. Já a ideia de região, ou a classificação do espaço a partir de critérios pré-estabelecidos permanece, aproximando-se da nova geografia.

$\begin{array}{llllll}\text { Caminhos de Geografia } & \text { Uberlândia - MG } & \text { v. 22, n. } 84 & \text { dez/2021 } & \text { p. 75-87 } & \text { Página } 79\end{array}$


Em relação à terceira "morte" da região, segundo Haesbaert (2010), esta se deu por meio de um movimento de continuação da abordagem anterior, o que inclui posições dentro do próprio materialismo histórico. Sobretudo entre os que acreditam que os processos de globalização irão impor uma sociedade em rede, em detrimento de uma sociedade regionalizada. Segundo o autor, há um discurso do "domínio inexorável da globalização em rede e da mobilidade que faria desaparecerem as regiões enquanto recortes espaciais contínuos, dotados de certo grau de estabilidade, singularidade e de homogeneidade interna" (p. 59). Porém, a partir do que chama "globalismo pós-moderno", Haesbaert (2010) alerta para o potencial estímulo à Geografia Regional e as propostas que "ressuscitam" o conceito de região, e sua capacidade de dar conta do des-ordenamento socioespacial atual.

Também, por volta dos anos setenta, surge uma nova corrente na geografia, a geografia humanista, que posteriormente influenciou na retomada da geografia cultural. O humanismo na ciência geográfica, ao contrário das demais correntes que emergiram após a década de cinquenta, e que buscavam distanciar-se da fase inicial da geografia, propõe exatamente o oposto. Os autores dessa vertente retomam a matriz histórica da disciplina, sobretudo a corrente possibilista, e buscam resgatar elementos do passado dessa ciência, entre eles a noção de região como quadro de referência social fundamental. Nas palavras de Gomes (2008, p. 67), "novamente, a região passa a ser vista como um produto real, construído dentro de um quadro de solidariedade territorial. Refuta-se, assim, a regionalização e a análise regional, como classificação a partir de critérios externos à vida regional".

\section{MORTE E VIDA BIORREGIÃO}

Propondo-se a realizar uma avaliação do atual momento da Geografia Regional e do conceito de região, Martins (2019) ressalta que, ao longo do desenvolvimento dessa ciência, diferentes trabalhos se dedicaram a essa tarefa. E destaca que, em diferentes contextos do desenvolvimento da ciência geográfica, surgiram distintas posições sobre o tema. Entretanto, o autor alerta que na atualidade a Geografia Regional não goza do mesmo prestígio do passado entre as práticas dos geógrafos e no desenvolvimento de pesquisas. Segundo ele, a Geografia Regional não tem sido ponto de partida dos trabalhos desenvolvidos por geógrafos, "por vezes se chega a ela por decorrência, ou seja, surge derivada de um estudo de caso específico" (MARTINS, 2019, p. 120). E nesse contexto, a região seria uma decorrência, não o ponto de partida, pois o centro do estudo seria o fenômeno regional.

$\mathrm{Na}$ tentativa de encontrar respostas para os motivos que levaram ao enfraquecimento dos estudos e identificações das regiões na ciência geográfica, esse autor analisa as circunstâncias e, a partir delas, apresenta sua posição. De início, alerta que essa categoria do pensamento geográfico teve seu desenvolvimento em função das demandas do Estado no tocante à gestão do seu território. $\mathrm{Na}$ atualidade, essa demanda ainda se impõe, pois, a partir da "necessidade legítima de administração e planejamento, as especificidades geográficas de um determinado território exigem a identificação de seu perfil regional e, com isso, adotam-se políticas específicas para cada região" (MARTINS, 2019, p. 120). Entretanto, ressalta que, em virtude da própria dinâmica dos territórios, é natural que novas teorias da região sejam desenvolvidas e redefinidas. Como já destacado, cada momento histórico determina uma geografia específica a partir da formação do território, da localização e distribuição dos entes geográficos (solo, clima, hidrografia, vegetação, atividades agrárias e industriais, rodovias, portos, ferrovias, etc.) e seus relacionamentos espaciais. Os entes geográficos, distribuídos e localizados, constituindo uma interação específica entre sociedade e natureza, encontram um eixo comum de articulação, a relação campo/cidade. Desse modo, no desenvolvimento desigual do eixo campo/cidade, ao longo da formação dos territórios, é onde está a gênese das regiões (MARTINS, 2019).

No intuito de justificar sua afirmação de que as teorias da região acompanham o desenvolvimento da relação campo/cidade, Martins (2019) ressalta a necessidade de observar o(s) critério(s) adotados para se delimitar uma região. Durante o período em que havia uma hegemonia do campo em relação à cidade, onde as atividades econômicas mais importantes eram a agricultura e a pecuária, a natureza e os seus elementos constituintes eram considerados determinantes para a definição de regiões. Nesse sentido, os trabalhos dedicados à região foram realizados de acordo com essa lógica. Quando há uma inversão dessa hegemonia, ou seja, quando a polaridade campo-cidade se inverte, o desenvolvimento industrial passa a ocupar o centro das discussões e, consequentemente, o desenvolvimento urbano e sua geografia correspondente. Em relação às teorias da região, estas passam a refletir o papel exercido pela indústria e pelos núcleos urbanos na reestruturação territorial. "Nesse contexto [...], a natureza, em seus elementos constituintes, deixa de ter destaque como critério a ser observado na delimitação regional" (MARTINS, 2019, p. 122).

$\begin{array}{llllll}\text { Caminhos de Geografia } & \text { Uberlândia - MG } & \text { v. 22, n. } 84 & \text { dez/2021 } & \text { p. 75-87 } & \text { Página } 80\end{array}$


Desse modo, a concepção de regiões polarizadas, definidas sob a ótica da intensidade de fluxos, e a função exercida por cada cidade, permitem o surgimento do positivismo lógico como contribuição teórica para o exercício de definir e identificar regiões. "O aprofundamento dessa posição teórica avançou na direção de uma abordagem a partir de modelos de divisão regional fundamentada no cálculo matemático. Uma posição seriamente atacada nos meios acadêmicos, todavia, segue sendo empregada pelo Estado" (MARTINS, 2019, p. 122). Assim, em relação aos estudos regionais, é possível destacar duas posições que, a princípio, divergem em virtude de a primeira considerar a interação sociedade/natureza como critério (a partir de uma realidade mais rural), enquanto a segunda privilegia fenômenos de polarização e redes de articulação do território (sob um contexto mais urbano). Todavia, tais posições possuem um denominador comum, o território de um Estado-nação, ou seja, atender às demandas do Estado continua sendo central nos estudos de Geografia Regional (MARTINS, 2019).

Questionando se os estudos regionais poderiam sobreviver para além das demandas do Estado, o autor afirma que o contexto disciplinar da ciência geográfica, extremamente fragmentado, não parece estar disposto a ter a região como categoria articuladora. Para ele, é fundamental reconhecer que a Geografia Regional, antes de ser um entre os diversos fragmentos disciplinares, é uma propriedade constitutiva de uma realidade. E que "a geografia de uma determinada realidade é produzida pelo entrecruzamento de diferentes elementos (o cultural, o político, o social, o pedológico, o hidrográfico, o econômico, etc.) e, simultaneamente, a nenhum deles se reduz" (MARTINS, 2019, p. 124).

Nessa perspectiva, faz-se necessário renunciar, de forma radical, à fragmentação e à ausência de conexões que a ciência geográfica desenvolveu entre os seus diferentes elementos constituintes. Entretanto, ao mesmo tempo, deve-se recolocar a existência do homem no centro dessa ciência, pois "se recolocarmos o homem e sua existência, repomos o que the é essencial e fundamental: sua articulação com a natureza e a dinâmica desta, pois a sobrevivência envolve a sobrevivência do ecossistema" (MARTINS, 2019, p. 125). Se impõe considerar todas as dimensões do existir humano e tomar a história em consideração, pois se trata de um fundamento essencial na construção processual deste ente social. Em relação à uma interpretação da Geografia Regional, a partir dos fundamentos do marxismo, Martins (2019) alega que a criação do conceito de formações econômico-sociais permitiu compreender a dimensão geográfica do desenvolvimento capitalista no país. Porém, destaca que, com a consolidação da geografia urbana, as dinâmicas da sociedade com a natureza são trocadas por fenômenos como fluxos e polaridades, e o entendimento com base nas relações econômico-sociais se enfraquece.

Alegando não ser possível definir regiões do ponto de vista antropogeográfico sob a vigência da geografia urbana do capitalismo, destaca que o que resta é realizar uma crítica propositiva. Assim, segundo Martins (2019), o melhor a fazer seria retomar a noção de biorregião desenvolvida por Gary Snyder. Para ele, a perspectiva antropogeográfica "retoma a geografia como condição da existência e sobrevivência humana, repondo os diferentes níveis de relação da sociedade com a natureza" (p. 129). $E$ nesse sentido, o conceito de biorregião ${ }^{3}$ poderia recolocar as cidades dentro da cadeia de relações estabelecidas com o ecossistema. O autor conclui afirmando que a Geografia Regional caiu em desuso em virtude de a ciência geográfica ter evoluído em uma direção que seus fundamentos não dão condição para as exigências da Geografia Regional, e que sua retomada necessita de uma mudança de propósitos e de uma fundamentação teórico-epistemológica correspondente.

\section{UMA MORTE MATADA É NECESSÁRIA}

Refletindo em torno da produção historiográfica regional brasileira e o papel do historiador regional, Albuquerque Jr. (2008) afirma que o conceito de região é pouco discutido e problematizado. Para ele, a região aparece como um dado a-histórico, um recorte espacial naturalizado, "ora como um recorte dado pela natureza, ora como um recorte político administrativo, ora como um recorte cultural, mas que parece não ser fruto de um dado processo histórico" (p. 55). O autor reforça que para a historiografia, a história se desenvolve na região, mas não existiria a história da região. O interesse estaria em compreender o que teria ocorrido no interior dos limites da região, e não a história de constituição desses limites. Segundo ele, recorrentemente têm-se negligenciado o espaço como elemento

\footnotetext{
${ }^{3}$ Segundo Berg (2002), a qual Martins faz referência ao propor a adoção do conceito de biorregião, esta seria definida em termos do padrão geral único de características naturais encontradas em um determinado lugar (clima, estações do ano, formas de relevo, bacias hidrográficas, solos, plantas e animais nativos). Ao mesmo tempo em que as pessoas também seriam consideradas como aspecto integral da vida do lugar.
}

$\begin{array}{llllll}\text { Caminhos de Geografia } & \text { Uberlândia - MG } & \text { v. 22, n. } 84 & \text { dez/2021 } & \text { p. 75-87 } & \text { Página } 81\end{array}$


constituinte do evento histórico, dedicando-se apenas a estabelecer e construir marcos temporais. $\mathrm{O}$ autor enfatiza que, na formação a partir de uma tradição historiográfica, o espaço é pensado como lugar de imobilidade, o que garantiria a perpetuação das memórias, inscrevendo-se em suportes espaciais para ganharem durabilidade, permanência, ou seja, no intuito de garantir sua monumentalização. E que "o espaço para os historiadores, tem sido pensado sob a chave do geográfico e o geográfico reduzido, em muitos casos, à dimensão física, à base empírica, aos condicionamentos naturais ou do meio, para usar um termo de largo uso nas ciências humanas, emergentes no século XIX" (ALBUQUERQUE JR., 2008, p. 57).

Recorrendo às origens da noção de região, Albuquerque Jr. (2008) lembra que esta remete a um espaço sobre um dado comando, que é regido (governado) por alguém, por alguma força. Um espaço sob controle, onde se exerce uma soberania após vencer um oponente. E alerta que o historiador que se interessar por qualquer recorte especial, que seja denominado região, obrigatoriamente, deve atentar para essas questões. Assim, os afrontamentos políticos, as lutas pelo poder, as estratégias de governos e de comando, os projetos de domínio e de conquista que resultaram no estabelecimento de fronteiras e limites, e que ora são reivindicados como naturais, ancestrais, legítimos ou até divinos, devem necessariamente ser observados. Nas palavras do autor, "falar em região implica em se perguntar por domínio, por dominação, por tomada de posse, por apropriação. [...] é também falar em subordinação, em exclusão, em desterramento, em banimento. [...] é se referir àqueles que não fazem parte dos projetos que deram origem a dado recorte regional" (ALBUQUERQUE JR., 2008, p. 58).

O autor supracitado alerta para o fato de que não há domínio sem um exercício resultante de uma dada experiência, um saber registrado e acumulado, uma estratégia a partir da repetição constante de métodos. Portanto, o historiador regional deve questionar os saberes que deram identidade, que definiram e demarcaram a região. Do contrário, a história regional "corre o risco permanente de se constituir em instância de veiculação e legitimação de um dado recorte regional, de se tornar um saber a serviço das forças. Dos interesses e projetos políticos que deram forma ou que sustentam um dado espaço dito e visto como regional" (ALBUQUERQUE JR., 2008, p. 59), sob o risco de ser aprisionada pelo discurso da identidade. Para Albuquerque Jr. (2008), é preocupante uma historiografia que se proponha a defender a região, porque isto implicaria em defender a dominação que a instituiu, e que a sustenta, além de ser uma postura acrítica diante dos saberes que a legitimam e a justificam. Conforme o autor, a melhor maneira de proceder com a noção de região é a desconstruindo, colocando-a em questão, suspeitando de sua existência naturalizada, e pensando as relações de poder e os saberes cristalizados, que deram contorno e realidade a um recorte regional.

As regiões são invenções humanas visando ordenar seja a natureza, quando vêem e definem regiões naturais, como faziam os geógrafos franceses da primeira metade do século XIX, seja a sociedade, quando vêem regiões econômicas, regiões políticoadministrativas, regiões jurídicas, regiões morais ou regiões nosográficas. As regiões nascem das práticas de significação e de ordenamento do mundo feito pelos homens. [...] que trazem imanente à sua realização estratégias de poder, de domínio, de controle, de separação, de inclusão e exclusão (ALBUQUERQUE JR., 2008, p. 57).

Nesse contexto, os regionalismos integrariam um conjunto de dispositivos criados pelo mundo moderno no intuito de dividir, classificar e hierarquizar os homens sempre no intuito de melhor governá-los, explorá-los e dominá-los. Para ele, "a região é uma das inúmeras formas de aprisionamento às quais a sociedade burguesa deu origem" (ALBUQUERQUE JR., 2008, p. 67). Cabendo a história (ao historiador) o papel de escolher entre reforçar as grades dessa jaula ou transformá-la em um casebre em ruínas.

\section{ESTÃO CANTANDO EXCELÊNCIAS}

Haesbaert (2010) lembra que as diversas áreas do conhecimento fazem suas próprias leituras em torno da noção de região. O autor afirma que, assim como a periodização se apresenta como uma questão central para os historiadores, a regionalização aparece como uma problemática central para os geógrafos, e que vem retomando sua força na atualidade. Primeiro em virtude da propalada globalização homogeneizadora provocar, concomitantemente, uma permanente fragmentação a partir de novas desigualdades, e da recriação da diferença nos diversos recantos do planeta. Segundo em função dos vários debates acadêmicos nas ciências sociais em torno da questão regional. $E$ terceiro em função do que classifica como "geografias regionais populares" (p.16), uma revalorização do regional por meio do discurso da mídia e do senso comum, que estimulam um olhar sobre a diversidade 
territorial e a valorização/recriação da diferença. Muito ligado a setores como o do turismo, um dos mais dinâmicos da economia.

Retomando o debate sobre as propostas que, nos últimos vinte anos, "ressuscitaram" a Geografia Regional e, consequentemente, o conceito de região, buscando dar conta do "des-ordenamento socioespacial" característicos desses novos tempos, destacamos que, para Haesbaert (2010), são múltiplas as linhas de abordagem, assim como são plurais as correntes teórico-filosóficas. Esse autor as divide em dois grandes agrupamentos, de acordo com o grau de ruptura com posições anteriores e/ou com a opção metodológica. Assim, têm-se, de um lado, "O pós-estruturalismo" e a ênfase contextual/local, na qual destaca as concepções de região lugar e de identidade regional. Enquanto de outro, o que classifica como "perspectivas neomodernas", com destaque para as concepções ligadas à noção de Estado-região, biorregião, teoria da estruturação, da des-continuidade da região e do mosaico cidades-região.

Em relação à obra de Albuquerque Jr., Haesbaert (2010), afirma que o autor estaria situado na perspectiva pós-estruturalista, que trata a região como um processo de invenção, partindo da análise do discurso. Conforme esse autor, Albuquerque Jr. traz uma importante contribuição ao buscar o elo entre produção discursiva e a contextualização das redes de poder que instituem e sustentam a região, a parir da ideia de região como uma invenção histórica. Por outro lado, ressalta ser uma perspectiva limitada em virtude de ocorrer um "deslocamento extremado" em relação às bases materiais (o realismo), na qual a região também é constituída. O autor reforça que, "ainda que centralizemos nossa análise sobre os sujeitos sociais, por maior que seja seu poder, eles nunca poderão abdicar de seu atrelamento aos condicionantes "naturais" diante dos quais se situam e com os quais articulam sua espacialidade" (p. 193). Em relação à noção de biorregião, reforça o amplo futuro que pode estar reservado a tal conceito, sobretudo se conseguir afastar-se de uma perspectiva puramente ecológica, como muitas vezes é abordado. Fazendo-se necessário incorporar a ele, além do debate em torno da relação cultura-natureza, as discussões sobre o biopoder, que envolve a relação indissociável entre o social e o natural.

No entanto Haesbaert (2010) alerta que pensar em região exige, de forma concomitante, pensar nos processos de regionalização. Nesse sentido, o autor destaca três caminhos possíveis para o tratamento da região e/ou regionalização, e, na sequência, propõe a utilização de uma nova abordagem, destacando ainda que a forma de regionalização pode variar, a depender das questões (objetivos) em jogo. No primeiro caminho - região como artifício - a regionalização corresponde a um instrumento de análise, que estaria centrado na figura do pesquisador, na investigação e nos procedimentos metodológicos. Nessa perspectiva, é possível regionalizar a partir de qualquer variável. No segundo região como fato - a regionalização corresponderia a um instrumento de práticas efetivas, ou seja, do uso concreto de diferentes sujeitos sociais em seus espaços vividos. O terceiro caminho - região plano/normativa - diz respeito a regionalização em um sentido "pragmático-político", como um instrumento de ação, de planejamento para intervenção (no real).

A partir da compreensão de que região/regionalização não está restrita a essas possibilidades, Haesbaert (2010) propõe e defende um quarto caminho (abordagem), o da região como um "artefato, tomada na imbricação entre fato e artifício e, de certo modo, também, enquanto ferramenta política" ( $p$. 109). Embora ressalte que não se trata de uma receita que possa ser aplicada sem restrições e em qualquer espaço, aponta para a necessidade de considerar as múltiplas dimensões do espaço em uma abordagem regionalista. Para ele, a dimensão política, mas também a cultural, a econômica, e até mesmo a própria dimensão natural, precisam ser conjugadas no que propõe denominar de articulação regional. Esta articulação se constituiria "na imbricação relativamente clara de múltiplas dimensões do espaço [...]. Nesse sentido, podemos falar de região como arte-fato enquanto envolvida em dinâmicas sociais efetivas que, aliás, reelaboram, na prática, as categorias região e regionalismo" (p. 120). Em relação ao termo região, propõe que seja designado a "espaços-momento que resultam efetivamente em uma articulação espacial consistente (ainda que mutável), complexa, seja esta de dominância econômica, política e/ou cultural" (p. 121). Visto que as articulações regionais do espaço, na atualidade, podem manifestar-se não somente na sua forma zonal tradicional e contínua, mas também de forma descontínua, inserida em uma lógica de articulação reticular.

E ainda que alguns ignorem a região como elemento-chave da geografia, e/ou se propale uma pretensa unidade (homogeneização) planetária, as questões centrais relativas ao debate sobre regiãoregionalização continuam, assim como movimentos de fragmentação mesmo em um contexto de globalização. Todavia, Haesbaert (2010) alerta que, antes de definir ou optar por um determinado conceito, faz-se necessário explicitar a problemática envolvida. O autor destaca ainda a inexistência de neutralidade nesse processo, pois "qualquer criação de "região", [...], não é uma mera

$\begin{array}{llllll}\text { Caminhos de Geografia } & \text { Uberlândia - MG } & \text { v. 22, n. } 84 & \text { dez/2021 } & \text { p. 75-87 } & \text { Página } 83\end{array}$


representação/generalização enquanto instrumento (necessário) para o entendimento do mundo, é também criação de realidades" [...] (p. 183). E nesse contexto, não se deve esquecer o próprio Estado, que continua a ser um dos principais produtores de conceitos aplicados e recortes regionais. Assim, como não se pode perder de vista que, em virtude da complexidade de situações, proposições teóricas e até do próprio "espaço-momento" em que estamos situados, não é racional termos a pretensão de resolver o dilema da regionalização de maneira unitária e universalmente generalizável. Uma vez que até mesmo espaços no interior de um mesmo país podem exigir importantes adaptações nos princípios de regionalização, e que, como já comentado, a regionalização pode variar de acordo com os objetivos em jogo.

\section{SANTOS}

Tratando da relação entre o que denomina "modo de produção técnico-científico" e a diferenciação espacial, Santos (1999) destaca que, nos primórdios da história, a ação dos modos de produção sobre o espaço ocorria sem mediações. Conforme esse autor, a partir do século XVI, com a expansão do capitalismo, o modo de produção tende a ser único, no entanto "a ação sobre os diversos territórios desse modo de produção tendencialmente único passa pela mediação das formações sociais constituídas sob a égide do estado nacional" (p. 06). Nesse sentido, essa mediação (do Estado, da sociedade civil e da configuração territorial) constitui um dado fundamental para explicar os diferentes impactos do modo de produção sobre os diversos países e regiões. Na visão dele:

O movimento de unificação, acelerado pelo capitalismo, hoje alcança o seu ápice, com a predominância em toda parte de um único sistema técnico, base material da globalização. [...] Os atores hegemônicos da vida econômica, social e política podem escolher os melhores lugares para sua atuação e, em consequência, a localização dos demais atores é condenada a ser residual (SANTOS, 1999, p. 08-09).

Nesse sentido, Santos (1999) adverte que os arranjos espaciais não ocorrem somente como nas regiões do passado, por meio de figuras formadas a partir de pontos contínuos e contíguos. Nas atuais condições, ao lado (ou em cima) dessas manchas há também constelações de pontos descontínuos, porém interligados, que constituem um espaço de fluxos reguladores. Portanto, por meio dessas novas configurações, novas categorias analíticas devem ser pensadas. Assim, o autor sugere que sejam admitidos dois recortes classificados como horizontalidades e verticalidades ${ }^{4}$, enfatizando a necessidade de uma análise a partir da ideia de espaço reticulado, sem perder de vista que apenas os atores hegemônicos se servem de todas as redes e se utilizam de todos os territórios.

Santos (1999) reforça ainda que, mesmo nesse contexto onde proclamam um espaço sem fronteira sobretudo em virtude da atuação das empresas transnacionais -, acreditar que o Estado se tornou desnecessário é um equívoco, assim como o é negar a ideia de região. $O$ autor reconhece (e reforça) que a velocidade das transformações mundiais, sobretudo no pós-guerra, fez com que a configuração regional do passado (baseada na territorialidade e identidade de um grupo, além da noção de exclusividade e limites) desmoronasse. Porém discorda da sua morte, alertando que, nas condições atuais, as regiões se tornaram campo de mediações, lugares funcionais do todo, espaços de conveniência, particularidade. Nesse contexto, a região continua a existir, todavia com um nível de complexidade jamais visto, onde nenhum subespaço do planeta escapa ao processo de globalização e fragmentação, de individualização e regionalização. "O momento atual faz com que elas se transformem continuamente, legando, portanto, uma menor duração ao edifício regional. Mas isso não a elimina, apenas ela muda de conteúdo" (SANTOS, 1999, p. 16).

\section{UMA "NOVA" CIGANA}

Em meio às perspectivas epistêmicas que entrelaçam a ciência geográfica, e, consequentemente, o conceito de região, faz-se necessário destacar aqui um conjunto de pensadores que vêm buscando uma renovação do pensamento crítico, desenvolvendo suas pesquisas a partir de uma perspectiva alinhada com o denominado pensamento descolonial latino-americano. De acordo com essa vertente, o fim do colonialismo na América Latina e da dominação econômica e política, não foram suficientes

\footnotetext{
${ }^{4}$ As extensões contínuas, formadas por pontos que se agregam sem descontinuidade, como na definição tradicional de região, são as horizontalidades. Os pontos no espaço que, separados uns dos outros, asseguram o funcionamento global da sociedade e da economia, constituem as verticalidades (SANTOS, 1999).
}

$\begin{array}{llllll}\text { Caminhos de Geografia } & \text { Uberlândia - MG } & \text { v. 22, n. } 84 & \text { dez/2021 } & \text { p. 75-87 } & \text { Página } 84\end{array}$


para decretar o fim da colonialidade como relação social, cultural e intelectual. Para que se compreenda melhor essa ideia, é preciso ter em mente que o colonialismo na América não ficou restrito aos meios coercitivos de dominação. "Não se trata apenas de reprimir os dominados, mas também da instituição e naturalização do imaginário cultural europeu como única forma de relacionamento com a natureza, com o mundo social e com a própria subjetividade" (CRUZ, 2017, p. 16), refletindo, inclusive, nos padrões de produzir conhecimento.

Sobre a ideia de "giro descolonial", é possível afirmar, segundo Cruz (2017), que se trata de "uma forma sintética de nomear uma inflexão epistêmica, ética e política nas Ciências Sociais latino-americanas e que coloca o nosso passado colonial como ponto de partida para pensarmos a especificidade de nossas sociedades" (p. 23). É necessário lembrar que, embora essa nova perspectiva epistemológica (ética e política) tenha ganho forte destaque na atualidade, ela deriva de um longo processo de lutas, de pensar e de agir contra o colonialismo e o seu legado. E entre os pontos fulcrais do pensamento descolonial está a crítica à uma retórica de poder, que trata o conhecimento como algo objetivo, neutro e universal, em que, no discurso epistemológico dominante, o conhecimento científico independe do tempo e do espaço, das contingências históricas, não tendo ligação com os sujeitos-autores que o produziram. Contudo "a produção do conhecimento não é abstrata, mas sim contextualizada, localizada, incorporada; ela está situada em histórias locais arraigadas em culturas e cosmovisões particulares, e traz as marcas dos sujeitos-autores que a produzem" (CRUZ, 2017, p. 26).

Nesse contexto, recorre-se às reflexões de Servilha (2017), que embora reconheça as contribuições das diversas interpretações do conceito de região, ao longo da trajetória do saber geográfico, aponta para outras possibilidades interpretativas desse conceito, inserido na perspectiva decolonial. $O$ autor propõe o tratamento do conceito de região a datar da sua importância e função histórica como instrumento de controle e integração territorial por meio de práticas estatais de colonialidade. Assim, propõe uma análise conceitual que permita reflexões em torno das relações entre: região/regionalização, colonialidade/descolonialidade e desenvolvimento/ subdesenvolvimento.

Servilha (2017) afirma que, embora o termo região esteja etimologicamente ligado às relações de poder, a ciência geográfica que predominou até a primeira metade do século XX "inviabiliza as relações políticas/de poder para se fundamentar na descrição das diferenciações do espaço. Regiões passam a ser delimitadas segundo relativa uniformidade paisagística, tendo em vista a caracterização de partes do todo" (p. 330). O autor alerta que assim como a conquista do Novo Mundo se deu em virtude da necessidade de expansão territorial comercial, possibilitada por uma política estatal de reconhecimento territorial, com relevante papel desempenhado pelas sociedades geográficas, o estabelecimento das regiões brasileiras seguem o mesmo percurso. Todavia não com fins de incorporação de novas áreas a um império, como foi no passado, mas no intuito de promover uma integração interna que possibilitasse a legitimação do poder estatal, ao mesmo tempo em que promovesse a expansão de um projeto nacional modernizador/capitalista (urbano-industrial) a partir de 1930. A esse processo, Servilha (2017) denomina "re-descoberta" da região pelo Estado, e destaca que só foi possível em função de uma "colonização intelectual" a partir de quatro mecanismos a serem observados no quadro 2.

\section{Quadro 2 - Mecanismos da "colonização intelectual"}

Homogeneização de sua população

Homogeneização do espaço

Um papel a ser definido na divisão social do trabalho

Uma realocação temporal
- A partir da ideia da existencia de um único povo, o "povo da região" (ex: povo Nordestino);

- A ideia de uma região homogênia a partir de sua pobreza (espaço-subdesenvolvido);

- Determinado a partir da inserção dependente da região numa emergente divisão terrritorial do trabalho;

- Regiões classificadas como "marcadas pelo atraso" dentro de uma lógica "modernizante".

Fonte: Adaptado pelo autor a partir de Servilha (2017).

No centro dessa "re-descoberta" da região estaria uma invisibilização dos sujeitos sociais, com suporte em olhares etnocêntricos, economicistas e desenvolvimentistas. A emergência de regiões de intervenção, assim como sua diferenciação em virtude de suas pobrezas, foi possível por meio de discursos que não estavam balizados nos problemas enfrentados nesses espaços, e sim em interesses de determinados grupos. Servilha (2017) adverte ser inquestionável a existência histórica de carências

$\begin{array}{llllll}\text { Caminhos de Geografia } & \text { Uberlândia - MG } & \text { v. 22, n. } 84 & \text { dez/2021 } & \text { p. 75-87 } & \text { Página } 85\end{array}$


sociais em determinados espaços, todavia alerta que o discurso de "fim da pobreza", sob a ótica de "regiões-problema", tornou-se um meio, e não um fim. Um mecanismo de legitimação, não no intuito de superar tais carências, mas para a incorporação desses espaços à integração estadual/nacional de forma dependente. De acordo com o autor, classificar uma área como subdesenvolvida para, a partir daí, instituir uma política pública desenvolvimentista, permite aos seus propositores, ainda que bemintencionados, "pouco mais do que a busca pela adequação de uma "área-desvio" aos padrões de desenvolvimento de espaços pré-escolhidos e pré-utilizados como referência (em geral, áreas urbanoindustriais)" (p. 339).

Assim, uma reflexão entre o processo de desenvolvimento e regionalização implantados no território nacional pelo Estado, reflete que independente de seus executores, há uma herança geográfica epistemológica re-descobridora. E, portanto, a descolonização do saber geográfico passa inevitavelmente por tentar responder "por que produzimos nosso saber e para que $(\mathrm{m})$ regionalizaremos o espaço, para, a partir daí, produzirmos reflexões e rupturas epistemológicas" (SERVILHA, 2017, p. 341). Tais reflexões/rupturas devem dar voz a outras possíveis formas de interpretar e viver a região, a partir de racionalidades, representações e práticas plurais, resistentes e emancipatórias.

\section{A HORA DO JUÍZO}

Ainda que a ideia de juízo remeta a um julgamento divino e derradeiro (final), não é essa a intensão. Busca-se, nesse tópico, apresentar algumas considerações sobre o conceito de região, a partir do diálogo estabelecido com os autores, sem a pretensão de esgotar o debate ou estabelecer verdades absolutas. Desse modo, inicialmente, faz-se necessário reforçar que, de fato, foram (e são) distintas as abordagens em torno desse conceito, ao longo da história do pensamento geográfico. Todavia é igualmente necessário atentar para o fato de que o conhecimento científico, sobretudo nas ciências sociais, tem como base a tentativa de compreender e explicar fenômenos (sociais) reais, realidades em transformação. Nesse sentido, concorda-se com Santos (1994, p. 167), quando afirma que "o tempo é a base indispensável para o entendimento do espaço", acrescentando ser fundamental considerar que os contextos históricos, políticos, socioeconômicos e espaciais (de onde se fala) refletem diretamente no teórico. Contextos estes que Haesbaert (2010) classifica como geo-históricos.

A progressiva relevância dos critérios sociais e econômicos para a definição das regiões, em detrimento das caraterísticas naturais. A tentativa de superar a regionalização submissa à lógica matemática, sob a ótica marxista ou pelo retorno ao possibilíssimo da geografia cultural. Os momentos em que a importância do conceito de região foi reconhecida em maior ou menor grau. Assim como a necessidade de se repensar esse conceito sob à luz da complexidade contemporânea. Ao nosso ver, inserem-se na tentativa de dar respostas às demandas referentes a cada momento (geo)histórico, o que pode ser observado, inclusive, nas distintas percepções de um mesmo autor a partir de contextos igualmente distintos. O que não significa neutralidade por parte de quem o propôs.

Embora o presente estudo reconheça as contribuições de alguns dos trabalhos que versam sobre o seu falecimento, considera-se que a região não está morta. Nem deliberadamente (morte matada), pelas mãos dos que advogam sua ruína, nem de causas naturais (morte morrida), pela perda de importância para a ciência geográfica. O que não se pode é manter as mesmas bases e conteúdos para regionalizar determinados espaços, sem considerar as novas formas de articulação para além das extensões espaciais contínuas e contíguas ou a noção de espaço reticulado. Atentando para o seu caráter seletivo e excludente, as consequências socioambientais desses processos, e tendo sempre em perspectiva as possibilidades e limites de suas abordagens diante da complexidade e das particularidades envolvidas. E, assim, deixar claro que não se trata de estabelecer modelos universais absolutos que não possam sofrer adaptações ou serem observados por outras lentes.

Outro aspecto desse debate é a necessidade de pensar a região associada à histórica relação com o atendimento às demandas do Estado. Embora seja legítima tal relação, é preciso atentar para os objetivos e interesses envolvidos, bem como suas consequências. Assim, considera-se que tão, ou até mais importante do que refletir em torno do significado do conceito de região, está a necessidade de se questionar: por que a região? Por fim, considera-se que a compartimentação da ciência geográfica em subgrupos (guetos), embora possa, no primeiro momento, contribuir para o aprofundamento de determinadas questões; sem o necessário cuidado, pode também extinguir uma das suas características mais ricas (e complexas), sua essência interdisciplinar. 


\section{AGRADECIMENTOS}

O presente trabalho foi realizado com apoio da Coordenação de Aperfeiçoamento de Pessoal de Nível Superior - Brasil (CAPES) - Código de Financiamento 001.

\section{NOTAS}

1. Em 2020 celebra-se o Centenário do poeta João Cabral de Melo Neto, nascido em 09 de janeiro de 1920.

\section{REFERÊNCIAS}

ALBUQUERQUE JR., D. M. O objeto em fuga: algumas reflexões em torno do conceito de região. Fronteiras, Dourados, MS, vol.10, no 17, p. 55-67, jan/jun, 2008. Disponível em: http://ojs.ufgd.edu.br/index.php/FRONTEIRAS/article/view/62/72. Acesso em 12 de jun. 2020.

BERG, P. Biorregionalismo (uma definição). Arquivos Digger, 2002. Disponível em: https://www.diggers.org/freecitynews/_disc1/00000017.htm. Acesso em 24 de set. 2019.

CORRÊA, R. L. Região e organização espacial. São Paulo: Editora Ática, 2000.

CRUZ, V. do C. Geografia e pensamento descolonial: notas sobre um diálogo necessário para a renovação do pensamento crítico. In: Geografia e giro descolonial: experiências, ideias e horizontes de renovação do pensamento. CRUZ, V. do C.; OLIVEIRA, D. A. de. (Org.). Rio de Janeiro: Letra Capital, 2017.

GOMES, P. C. da C. Geografia e modernidade. Rio de Janeiro: Bertrand Brasil, 2011.

O conceito de região e sua discussão. In: Geografia: conceitos e temas. CASTRO, I. E. de.; GOMES, P. C. da C.; CORREAA, R. L. (Org.). Rio de Janeiro: Bertrand Brasil, 2008.

HAESBAERT, R. Regional-global: dilemas da região e da regionalização na geografia contemporânea. Rio de janeiro: Bertrand Brasil, 2010.

LENCIONI, S. Região e geografia. São Paulo: Editora da Universidade de São Paulo, 1999.

MARTINS, E. R. Região e Geografia Regional. In: A necessidade da geografia. CARLOS, A. F. A.; CRUZ, R. C. A. (Org.). São Paulo: Contexto, 2019.

MELO NETO, J. C. de. Morte e vida Severina e outros poemas. Rio de Janeiro: Alfaguara, 2007. RODRIGES, N.; SILVA, J. N. Ritos fúnebres populares do Maranhão. São Luiz: Edições UFMA, 1981.

SANTOS, M. Modo de produção técnico-científica e diferenciação espacial. Revista Território, Rio de Janeiro, ano IV, n. 6, p. 5-20, jan./jun, 1999. Disponível em:

http://www.laget.eco.br/pdf/06_2_santos.pdf. Acesso em out. 2019.

Técnica, espaço, tempo: globalização e meio técnico-científico infomacional. São Paulo: Hucitec, 1994.

SERVILHA, M. de M. Região, colonialidade e subdesenvolvimento. In: Geografia e giro descolonial: experiências, ideias e horizontes de renovação do pensamento. CRUZ, V. do C.; OLIVEIRA, D. A. de. (Org.). Rio de Janeiro: Letra Capital, 2017.

SUERTEGARAY, D. M. A. Notas sobre Epistemologia da Geografia. Cadernos Geográficos, Florianópolis, n. 11, mai. 2005.

Recebido em: 10/08/2020

Aceito para publicação em: 17/11/2020 